\title{
Genetic Diversity of a Collection of Solanum macrocarpon from Burkina Faso Revealed by Microsatellite Markers
}

\author{
Kabore Boukare*, Sawadogo Boureima, Kiebre Mariam, Tiama Djakaridia, Kiebre Zakaria, \\ Traore Renan Ernest, Sawadogo Mahamadou, Bationo-Kando Pauline
}

Training and Research Unit in Life and Earth Sciences, University Joseph KI-ZERBO, Ouagadougou, Burkina Faso

Email address:

kab85.bouba@gmail.com (K. Boukare), boukarkabor18@yahoo.fr (K. Boukare)

${ }^{*}$ Corresponding author

To cite this article:

Kabore Boukare, Sawadogo Boureima, Kiebre Mariam, Tiama Djakaridia, Kiebre Zakaria, Traore Renan Ernest, Sawadogo Mahamadou, Bationo-Kando Pauline. Genetic Diversity of a Collection of Solanum macrocarpon from Burkina Faso Revealed by Microsatellite Markers. International Journal of Genetics and Genomics. Vol. 7, No. 2, 2019, pp. 27-33. doi: 10.11648/j.ijgg.20190702.12

Received: March 17, 2019; Accepted: June 13, 2019; Published: June 27, 2019

\begin{abstract}
Solanum macrocarpon is an important vegetable native to Africa, with leaves and fruits. It is a potential source of income and nutrients that contribute to the nutritional balance of the local population's food intake. However, S. macrocarpon did not attract the interest of researchers in relation to other Solanum species. Indeed, knowledge of the genetic diversity of $S$. macrocarpon (Gboma Eggplant) in Africa is limited. Although agronomic variations and relationships generally reveal important traits of interest to breeders. This study attempts to estimate the genetic diversity of a collection of $S$. macrocarpon (32 accessions) from Burkina Faso using SSR markers. The results show that eleven (11) of the 22 SSR markers tested were informative for phylogenetic analysis and could serve as a perfect reference for diversity studies. The 11 polymorphic SSR primers selected amplified 22 alleles with an average of 2 per primer. The polymorphism information content (PIC) varied from 0.212 for emg01B17 to 0.437 for emd15D09. The genetic distances between the accessions studied varied from 0 to 0.68 and made it possible to distinguish three genetic groups. The expected $\mathrm{Nei}(\mathrm{He})$ heterozygosity for the genetic group ranged from 0.140 for group III to 0.261 for group I. The eleven pairs of SSR markers sufficiently discriminated against the accessions of Solanum macrocarpon. The results of this study will be useful for the conservation and genetic improvement of the $S$. macrocarpon species in Burkina Faso.
\end{abstract}

Keywords: Genetic diversity, Polymorphism, Solanum macrocarpon, SSR Markers, Burkina Faso

\section{Introduction}

Solanum macrocarpon L. (Gboma Eggplant) belongs to the genus Solanum, the subgenus Leptostemonum and the section Melongena (Miller) Dunal [1]. The cultivated $S$. macrocarpon was domesticated from $S$. dasyphyllum Schum. and Thonn., wild relatives [2]. It is cultivated throughout tropical Africa, especially in humid regions. The species is also cultivated in South America and Asia [3]. According to the [2], Gboma Eggplant is grown along the coasts of West Africa (Ghana, Nigeria, Togo, Ivory Coast and Benin), East and South (Malawi, Zambia, Zimbabwe and Mozambique). In Burkina Faso, $S$. macrocarpon is grown in the three border provinces (Nahouri, Sanguié and Sissili) with Ghana [4].

The fruits and leaves of $S$. macrocarpon are eaten fresh or simmered with other vegetables such as Amaranth and Cabbage. An excellent source of minerals, fibers and proteins [5-6], the marketing of $S$. macrocarpon leaves and fruits provides important income to many households [7]. It is also used in traditional medicine for the treatment of various conditions, ranging from weight loss, asthma, skin infections, rheumatic diseases, gastroesophageal reflux disease, constipation and diabetes [8].

Despite its nutritional and economic importance, knowledge about the genetic diversity of Gboma Eggplant in Africa is limited. The limited research on S. macrocarpon has been conducted on genetic variability among accessions in Ghana using various agronomic traits [9]. In Burkina Faso, agro-morphological characterization has shown the existence of diversity within accesses to $S$. macrocarpon despite the small-cultivated area [5]. Yet, the estimation of genetic 
diversity is essential for the effective control, consumption and appropriate use of plant genetic resources [10]. According to the [11-12], the genetic diversity of cultivated species is the essential product of plant breeding. Indeed, the evaluation of genetic resources is crucial for breeders in order to establish variation between individuals on the one hand and on the other hand to select popular cultivars according to changes in consumer demand. In addition, biochemical traits, genealogical analysis and genetic fingerprinting using molecular markers [13-14] can assess the genetic diversity of breeding material. SSRs or microsatellites are the most commonly used markers for diversity studies. They are short, tandem, repeated nucleotide units of one to five nucleotides and their value for genetic analysis lies in their polyalignment, codominant inheritance, relative abundance, genotypic coverage and the relevance of high throughput PCR platforms [15]. A number of workers have developed SSRs for eggplant, including genomic SSRs by the [16-17] and genic SSRs by the [18] which they tested primarily on eggplant cultivars. This study was undertaken to use genomic SSR to determine the genetic diversity of thirtytwo accessions of Solanum macrocarpon.

\section{Materials and Methods}

\subsection{Plant Materials}

Thirty-two (32) local accessions from three provinces of Burkina Faso were used in this study (Figure 1), including sixteen (16) from Sissili, thirteen (13) from Sanguié and three (3) from Nahouri (Table 1). These accessions were sown and cultivated directly on the ground. The nursery was watered regularly morning and evening to ensure good seedlings growth. The young leaves of each accession were collected, weighed and used to extract genomic DNA.

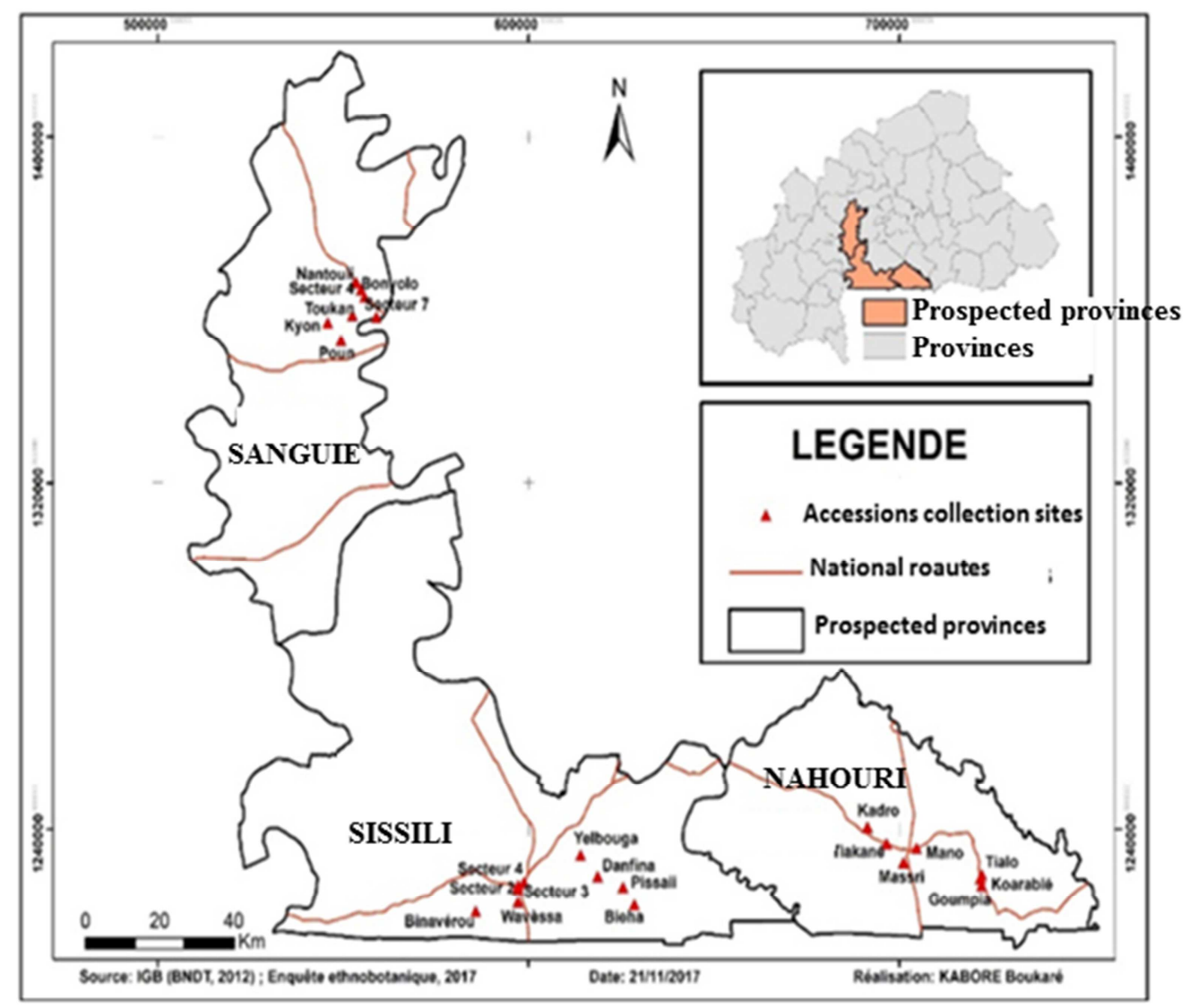

Figure 1. Investigated and collection sites of Solanum macrocarpon accessions cultivated in Burkina Faso.

Table 1. Characteristics of the studied Solanum macrocarpon accessions.

\begin{tabular}{llll}
\hline Number & Status & Provinces & Climatically zones \\
\hline 16 & Cultivated & SISSILI & Sudanian \\
3 & Cultivated & NAHOURI & Sudanian \\
13 & Cultivated & SANGUIE & Sudano-sahelian \\
\hline
\end{tabular}

\subsection{SSR DNA Marker Analysis}

Twenty-two (22) Single Sequence Repeat (SSR) microsatellites markers were used in this study. They have been developed specifically for genetic diversity studies of $S$. melongena by the $[16,19]$. These are markers already used by the $[18,20]($ Table 2$)$. 
Table 2. Characteristics of the twenty-two SSR markers used [20-21].

\begin{tabular}{lllll}
\hline Entry No. & Primer name & Forward sequence & Reverse sequence & Tm $\left({ }^{\circ} \mathbf{C}\right)$ \\
\hline 1 & emb01G19 & AATTAAGGCTGAGAGGGGAAGACG & AAAGGAGGAAAGGGAAAGGGAAAG \\
2 & emf01G17 & ATGGCAACTGATAATGCAGACGTG & GTTTCTCACTCTTACATGTGGCTGGC \\
3 & emh21J12 & ACAGAACAATTCACCAGCAGTCAA & GTTTAGGAACAGGGAAAATCGTATCGGT & 52.5 \\
4 & eme25D01 & AGTCCCAACCAAAATCGTAGAGGC & GTTTCACTGAAGGATGTGGAGTGTGA & 52.6 \\
5 & emg11A06 & AGTGCTAATATGCAAGGGGAATGG & GTTTACGGTGATCTTTCCGTATTCCAAA & 51.3 \\
6 & emg01B17 & ACAAGGCTCAAAGTCACAAGTCAA & GTTTGGCTCTGCCCCTAACATCTACAAA & 51.9 \\
7 & emf11H23 & ATTCTGAAAACAAGAGCAGCCCTC & GTTTCTCAACACCTCTGTGTCTGGCAT & 52.6 \\
8 & emg11I03 & ATTAGGCACAAGTGCCACCTGAAT & GTTTCAGCCGGGAGTCTGATAGGTAAAA & 52.7 \\
9 & emf11L21 & ATAGCCTAGGTAACGTACCCCTCG & GTTTGGCTCTATTTCCTGGCTTTCAT & 53.7 \\
10 & emd12B05 & ACGGAGTAGGCTCGGAGCGTGATATT & GTTTGAAAGGGCAAAAAGTCCAAACAAC & 54.0 \\
11 & emd05F05 & ACGGGGGTGTCTCATTACACTACTGG & GTTTACCCGTTCCTCAGCTTATAGACCC \\
12 & emf01O01 & AGGAATTGGATTTCCACTCATACG & GTTTGGAAGATGAGATTCCTTTCTTGA & 49.5 \\
13 & emf21K08 & ATCAATGACACCCAAAACCCATTT & GTTTGAAAACCCAATACAAATCCGA & 47.5 \\
14 & emb01F16 & AAAACAGAAGCAAAGTCGGCAGTC & GTCCACCAACACCTTACCATCCTC \\
15 & emh11G21 & ATGTGTGAACTCAAATGGAAGGGA & GTTTCGAATTGCTTTTTGGTGCATGTAG \\
16 & emf21P02 & ATGAAGCAGATCTTTCGACTGCAC & GTTTAGGCCAAGGATGTCAAACTGGT & 50.4 \\
17 & emh05B02 & ATACCAAAGACACGTTGGGATCAT & GTTTCTAGGAGAGCATCTCCCTCCCT & 51.8 \\
18 & emd15D09 & ATAATGGGCAAAGGGTCCATTAAC & GTTTGGAACCATGCAGTACCAGACATGA & 51.9 \\
19 & emj04E17 & ACACGCTGCTGAAATAGTTCTTAG & GTTTCGAGTTATGCTGAGAGCAGTGTGA & 52.1 \\
20 & emh11N11 & ATTCAGTTCTTCGCTTTGGAGCTT & GTTTCCAAACCCGACCCATCCTAAATAA & 51.2 \\
21 & emj01G23 & ATTAACTGGCCATGAACACCTGTC & GTTTGACCTCAATAAAGGGGGTTTGCAT & 52.0 \\
22 & emd18B04 & ATTTCTGAGGTTTAACATCGCCGT & GTTTCGGAGGAGAGCAAGTTCTGCTTTA & 51.9 \\
\hline
\end{tabular}

\subsection{DNA Extraction and Quantification, PCR Amplification, and Gel Electrophoresis}

The extraction of genomic DNA was carried out at the Molecular Biology Unit of the Plant Genetics and Breeding Team at Joseph KI-ZERBO University. Young leaves of fully developed and undamaged Solanum macrocarpon were collected from the genotypes of each cross. DNA was extracted using the DNAzol method [22] readapted to the species $S$. macrocarpon. As a result, $0.1 \mathrm{~g}$ of fresh young leaves from each sample were finely ground in a mortar in the presence of $750 \mu \mathrm{l}$ of ultra-pure water. The resulting shred was centrifuged in a 2 $\mathrm{ml}$ eppendorf tube at $10,000 \mathrm{rpm}$ at $4^{\circ} \mathrm{C}$ for 10 minutes. At the end of this first centrifugation, the supernatant was removed and then a volume of $200 \mu \mathrm{l}$ of a DNAzol solution was added to the pellet. After homogenization, the tubes were placed in a water bath at $65^{\circ} \mathrm{C}$ for 2 hours. After the 2 hours, the tubes were centrifuged again at $10,000 \mathrm{rpm}$ at $4^{\circ} \mathrm{C}$ for 15 minutes. This time, the supernatant was collected in new tubes and stored at a temperature of $-20^{\circ} \mathrm{C}$.

Polymerase chain reaction (PCR) was performed using the optimized SSR amplification conditions for S. macrocarpon. Each $20 \mu \mathrm{L}$ PCR reaction consisted of $3 \mu \mathrm{l}$ genomic DNA, $1 \mu \mathrm{l}$ each of forward and reverse primer and $4 \mu \mathrm{l}$ premix PCR (1U Taq DNA polymerase, $250 \mu \mathrm{M}$ Tris-HCL, $10 \mathrm{mM} \mathrm{KCl}, 1.5$ $\mathrm{mM} \mathrm{MgCl}_{2}$ ). Amplifications were carried out in a Thermal Cycler with the amplification conditions of initial denaturation at $94^{\circ} \mathrm{C}(30 \mathrm{~s}), 30$ cycles of $94^{\circ} \mathrm{C}(30 \mathrm{~s})$ denaturation, $47-58^{\circ} \mathrm{C}$ annealing $(1 \mathrm{~min})$ and $72^{\circ} \mathrm{C}(1 \mathrm{~min})$ extension, followed by one cycle at $72^{\circ} \mathrm{C}(5 \mathrm{~min})$ final extension.

Agarose gel electrophoresis was used to separate the amplified DNA fragments. PCR amplification products were electrophoresed in $2 \%$ agarose gel using $1 \mathrm{X}$ Tris-borate EDTA (TBE) solution. Electrophoresis was carried out for 2 hours at 90 V. The gels were stained with BET (Bromide Ethidium), used by standard methods of [23] and statement under ultra-violet
(UV) light. The DNA ladder (Bioline GmbH, Germany) was used in each gel as molecular size standard.

\subsection{Data Analysis}

A binary matrix based on the presence (1) or absence (0) of gel bands was performed for electrophoresis analysis profiles. The markers that gave clear bands were selected for statistical analysis. Three software programs were used (GenAlEx, Genetix 4.0.5.2 and Darwin 6.0.4). Genetic parameters were calculated using GenAlEx software to assess the level of diversity of all collections. These are the average number of alleles per locus (At), the number of effective alleles (Ae), the polymorphism rate $(\mathrm{P})$, the Shannon diversity index (I), the expected heterozygosity (He) and the polymorphic information content (PIC). The diversity structure has been realized with Darwin software version 6.0. But the Genetix software was used to calculate the genetic distance between the genetic groups formed. Fstat software version 2. 9. 3. 2. for estimating the genetic differentiation index between populations (Fst).

\section{Results}

\subsection{Level of SSR Marker Polymorphism}

Of the 22 SSR primers selected for polymorphism, 11 SSR markers were found to be polymorphic for all accessions (Table 3). The 11 polymorphic SSR markers amplified 22 alleles in the eggplant access collection. 32 accessions of $S$. macrocarpon tested showed considerable polymorphism. The number of alleles per primer is between 2 . The number of effective alleles (Ae) ranges from 1.258 (emg01B17) to 1.779 (emd15D09) with an average of 1.433 for all primers. The expected heterozygosity $(\mathrm{He})$ of the collection is 0.372 and ranges from 0.219 to 0.451 respectively for the emg $01 \mathrm{~B} 17$ and 
emd15D09 primers. As for the Shannon diversity index (I), with an average of 0.543 for all markers, it is included 0.628 for the emd15D09 marker and 0.361 for emg01B17. The polymorphism information content (PIC) ranged from 0.212 (emg01B17) to 0.437 (emd15D09) with an average of 0.359 .

Table 3. Level of diversity of markers tested.

\begin{tabular}{llllll}
\hline Primers & $\mathbf{A}^{\mathbf{t}}$ & $\mathbf{A}_{\mathbf{e}}$ & $\mathbf{I}$ & He & PIC \\
\hline emg11A06 & 2 & 1.777 & 0.626 & 0.450 & 0.435 \\
emg01B17 & 2 & 1.258 & 0.361 & 0.219 & 0.212 \\
emf11H23 & 2 & 1.599 & 0.543 & 0.379 & 0.358 \\
emf11L21 & 2 & 1.704 & 0.602 & 0.426 & 0.413 \\
emf1P02 & 2 & 1.562 & 0.544 & 0.371 & 0.360 \\
emd15D09 & 2 & 1.779 & 0.628 & 0.451 & 0.437 \\
emj04E17 & 2 & 1.644 & 0.579 & 0.404 & 0.391 \\
emj01G23 & 2 & 1.470 & 0.500 & 0.330 & 0.320 \\
emb01G19 & 2 & 1.410 & 0.482 & 0.299 & 0.290 \\
emh11G21 & 2 & 1.742 & 0.616 & 0.440 & 0.426 \\
emd18B04 & 2 & 1.458 & 0.492 & 0.324 & 0.314 \\
\hline Mean & 2 & 1.433 & 0.543 & 0.372 & 0.359 \\
\hline
\end{tabular}

Legend: $\mathrm{A}^{\mathrm{t}}$ : total number of alleles, $\mathrm{A}_{\mathrm{e}}$ : number of effective alleles, He: expected heterozygosity, PIC: content of polymorphism information, I: Shannon diversity index, P: polymorphic percentage of loci.

\subsection{Structuring the Genetic Diversity of the Collection of $S$. Macrocarpon from Burkina Faso}

The estimated genetic distance for all accessions ranged from 0 to 0.68 . On the one hand, the short genetic distance between two individuals ( 0 ) suggests a similarity with the loci studied. On the other hand, the highest distance $(0.68)$ reflects the total divergence between these individuals. Examination of the dendrogram of the total population makes it possible to distinguish three distinct genetic groups (I, II, III) at the threshold of the $5 \%$ confidence interval independent of the collection area. Group I includes 8 accessions, Group II 14 accessions and Group III 10 accessions.
The estimation of the genetic diversity parameters of the three genetic groups identified by the dissimilarity matrix shows that the number of effective alleles varies from 1.251 for Group III to 1.442 for Group I. The expected heterozygosity ranged from 0.140 for Group III to 0.261 for Group I. The rate of polymorphism is $68.18 \%$ (Group I), $68.18 \%$ (Group II) and 36.36\% (Group III). Finally, the Shannon diversity index and the polymorphic information content range from 0.205 to 0.387 and 0.156 to 0.299 for Groups III and I respectively. In general, diversity parameters are more important in Group I while Group III has the lowest values (Table 4).

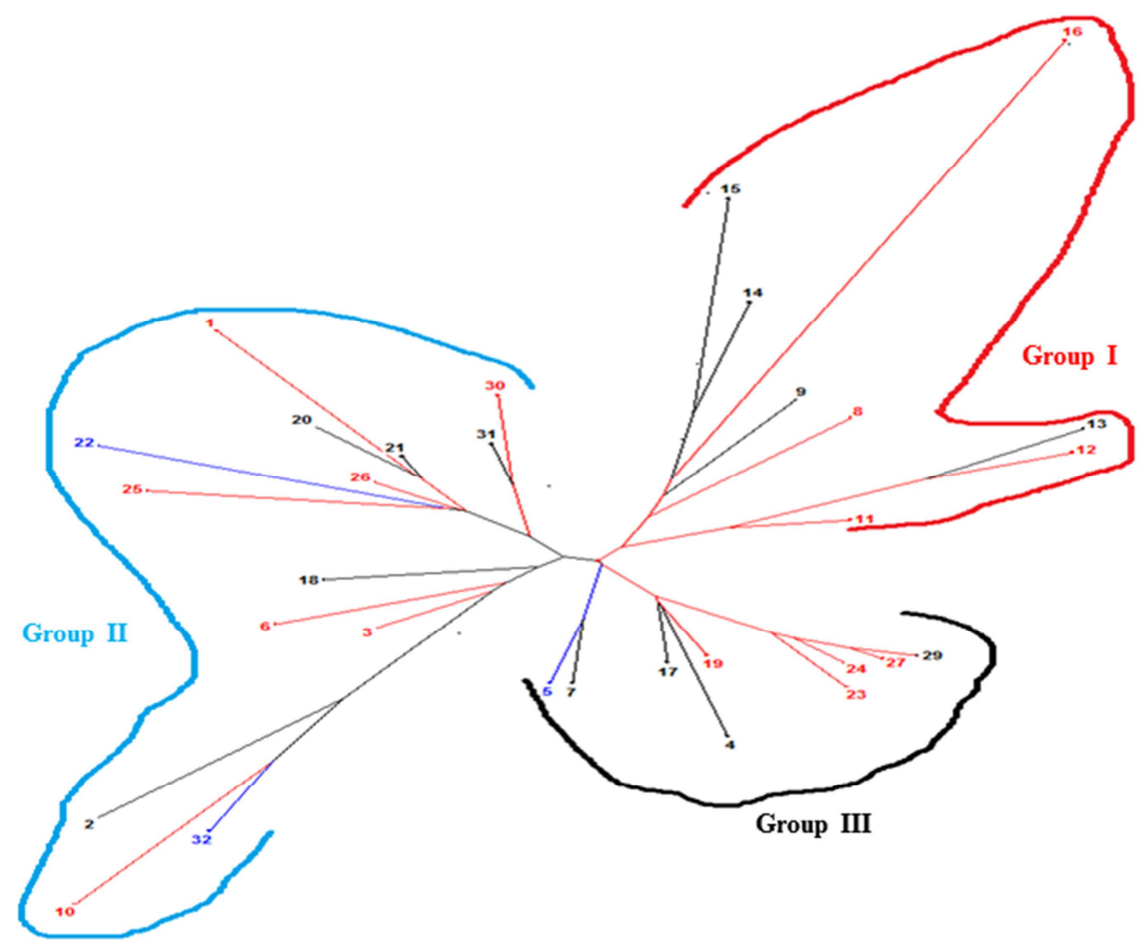

Legend: Numbers 1 to 32 represent the individuals studied: (Red for Sissili, Black for Sanguié and Blue for Nahouri)

Figure 2. Radial representation of the dendrogram of S. macrocarpon accessions, constructed from the dissimilarity matrix according to the NeighbourJoining method. 
Table 4. Distribution of genetic diversity of S. macrocarpon according to groups.

\begin{tabular}{llllllll}
\hline Groups & $\mathbf{N}$ & $\mathbf{A}^{\mathbf{t}}$ & $\mathbf{A}_{\mathbf{e}}$ & $\mathbf{I}$ & He & PIC & P(\%) \\
\hline Group I & 8 & 20 & 1.442 & 0.387 & 0.261 & 0.299 & 68.18 \\
Group II & 14 & 21 & 1.406 & 0.357 & 0.238 & 0.256 & 68.18 \\
Group III & 10 & 21 & 1.251 & 0.205 & 0.140 & 0.156 & 36.36 \\
\hline
\end{tabular}

Legend: $A^{t}$ : total number of alleles, $A_{e}$ : number of effective alleles, He: expected heterozygosity, PIC: Polymorphic Information Content, I: Shannon Diversity Index, P: polymorphic loci rate, N: Number of individual.

\subsection{Differentiation of Genetic Groups}

The average value of the inter-population differentiation index (Fst) is 0.233 ; showing that intra-population variation and the rest of this variability $(23.3 \%)$ explain a large part of the total genetic variability $(76.67 \%)$ is attributed to interpopulation variation. The matrix of genetic distances between populations shows a difference of 0.091 between populations II and III and 0.105 between populations I and III. These relatively low values indicate that populations are genetically similar and belong to the same genetic group (Table 5). Groups II and III are very close genetically to each other (the distance is 0.091 , quite close to 0). In contrast, Group III is significantly further away from the other two I and II (distances of 0.103 and 0.105 , respectively). The Principal Coordinate Analysis (PCoA) indicates axis 1 (Coord.1) explains $60.69 \%$ of the total genetic variation, and axis 2 (Coord.2) explains 39.31\% and confirms the hypothesis that groups II and III are genetically close (Figure 3 ).

Table 5. Inter-group genetic differentiation of S. macrocarpon.

\begin{tabular}{llllll}
\hline \multirow{2}{*}{ Genetic groups } & \multicolumn{2}{l}{ Minimum distance from Nei } & \multicolumn{2}{l}{ Differentiation index (Fst) } \\
\cline { 2 - 5 } & Group I & Group II & Group III & Group I & Group II \\
\hline Group I & 0 & & & 0 & Group III \\
Group II & 0.103 & 0 & & $0.199^{*}$ & 0 \\
Group III & 0.105 & 0.091 & 0 & $0.257^{*}$ & $0.245^{*}$ \\
\hline
\end{tabular}

* = Significant.

Principal Coordinates (PCoA)

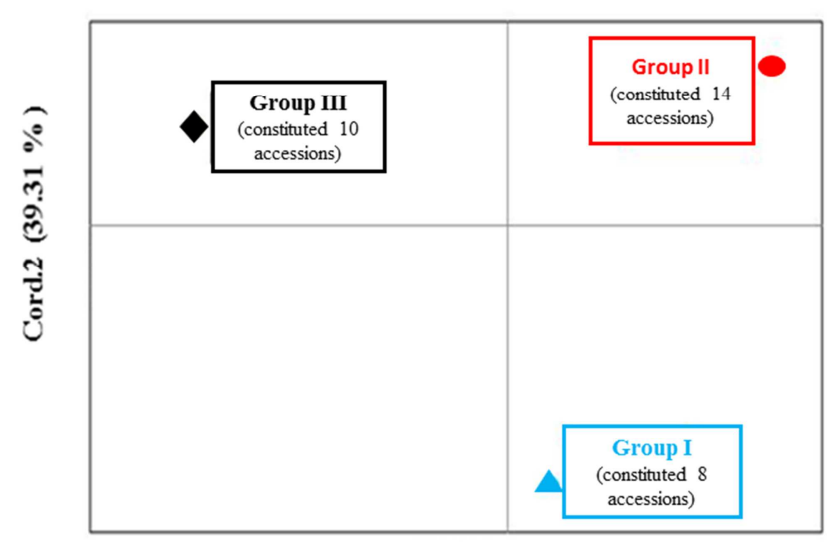

Cord.1 (60.69\%)

Figure 3. Representation in the PCoA plan $1 / 2$ of the three genetic groups.

\section{Discussion}

With a polymorphism rate of $91.67 \%$, the markers used were informative on the diversity of the accessions studied. Although significantly lower than the rate $(97 \%)$ reported by the [20], this rate, which is higher than that reported $(65.12 \%)$ by the [24], testifies to their effectiveness in analyzing the genetic diversity of the Solanum genus. On the basis of eleven identified polymorphic SSR markers, a diversity has been identified within the $S$. macrocarpum collection.

The average number of alleles per locus observed (2) is low compared to those obtained by the [18] (2.87) and by the [25] (2.34), respectively on eggplant varieties in India and Spain. This difference could be explained by a low diversity of Burkina Faso's accessions, on the one hand, the size of the sample and, on the other hand, the nature of the markers used. Indeed, the former used the same SSRs markers but on wild genotypes of Brinjal genotypes and the latter used SNPs markers. Although low, the average number of alleles per locus is however higher than that of [26] who reported an average number of alleles of 1.58 in S. aethiopicum Kumba group. These differences would be explained by genotypic diversity, sample size and the origin of the plant material. Indeed, the allelic richness of a population is known to depend on the sample size, since the chances of discovering a new allele increase each time a new individual is observed [27]. Similarly, according to the [28], the number of alleles per locus is affected by several factors such as genotype, primer sequences and minor variations in amplification protocols.

The polymorphism information content (PIC), which indicates not only the number of alleles detected but also the relative frequency of these alleles is an important means of estimating genetic diversity [29]. Indeed, the low values of the polymorphic information content $(0.359)$, the average number of effective alleles (1.433) and the expected heterozygosity values ranging from 0.299 to 0.451 could also be due to the low level of diversity within the collection. The same is true of the small genetic distances between the accessions studied, which varied from 0 to 0.68 , thus reflecting low genetic variability within the population. These low values observed would also be because the 
primers used in the study were developed on the $S$. melongena species and are therefore not species-specific. According to the [30], the diversity revealed in a collection is all the lower as the markers used are developed on another species. The low values could also be explained by genetic erosion of the species caused by the sharp decline in the cultivation of the species in Burkina Faso. Although the area under cultivation of $S$. macrocarpom is reduced to three neighbouring provinces, the genetic basis of the species is comparable to that of $S$. eathiopicum grown throughout the country. Indeed, the value of 0.37 of the expected heterozygosity revealed by this study is significantly similar to that of [26, 31] who observed respectively an expected heterozygosity of 0.34 and 0.37 on a national collection of $S$. aethiopicum using EST-SSRs markers. The low diversity observed on these species can be attributed to the preferential self-pollinating reproduction mode of the genus Solanum. In general, in Burkina Faso, the diversity of a cultivated species, especially vegetable species, is revealed from a collection of a single climatic zone [26, 32-33]; this is due to the way seed is managed and the migratory flow of the population. In Burkina Faso, seed exchanges between farmers can lead to long-distance migration of plant material.

The study of the structuring of accessions showed three distinct groups I, II and III with intergroup Fst of 0.199 between II and I; 0.245 between II and III and 0.257 between III and I. According to the [34-35], Fst values between 0 and 0.05 reflect low genetic diversity between subpopulations, moderate when statistical differences are between 0.05 and 0.15 ; high when they are between 0.15 and 0.25 and very high when statistical differences between subpopulations are more than 0.25 . Thus, these generally high values indicate a large discrepancy between the three groups observed.

\section{Conclusion}

Molecular characterization revealed the existence of genetic diversity throughout the entire collection of $S$. macrocarpon grown in Burkina Faso. It also revealed that diversity parameters remain relatively low due to the species' preferred self-pollinating reproductive mode. A three-group structure was obtained by the Neighbor-joining dissimilarity analysis. Indeed, the assessment of genetic dissimilarity or similarity is important not only for species improvement efforts, but also for the effective management and protection of genetic resources and for breeding purposes, in order to allow the possibility of rapid combination or verification of genetic material. The results of this study may be useful in the case of conservation and genetic improvement of Solanum macrocarpon in Burkina Faso.

\section{References}

[1] Whalen M. D., 1984. Conspectus of species groups in Solanum subgenus leptostemonum Gentes Herbarum, 12 (4), 179-282.
[2] Shippers, R. R. 2002. African Indigenous Vegetables: An overview of the cultivated species 2002 Revised Version on CD-ROM. Natural Resources Institute, Chatham, UK. pp. 214.

[3] Marchoux G., Gognalons P., Sélassié K. G. 2008. Virus des Solanacées. Du génome viral à la protection des cultures. Edition. Quae, Paris, France, 846p.

[4] Kaboré B., Traoré R. E., Kiébré Z., Sawadogo B., Kiébré M., Nanema K. R., Sawadogo M., Bationo/Kando P. 2018. Phenotypic diversity of accessions of Gurunsi eggplant (Solanum macrocarpon L.) from Burkina Faso. Glob. J. Crop Soil Sci. Plant Breed. Vol. 6 (1), pp 296-305.

[5] Agoreyo B. O., Obansa E. S. and Obanor E. O. 2012. Nutritional and phytochemical analyses of varieties of Solanum melongena. Science World Journal, 7 (1): 23-42.

[6] Nyadanu D. and Lowor S. T. 2014. Promoting competitiveness of neglected and underutilized crop species: Comparative analysis of nutritional composition of indigenous and exotic leafy and fruit vegetables in Ghana. Genetic Resources and Crop Evolution, DOI: 10.1007/s10722-0140162-x.

[7] Adeyeye E. I. and Adanlawo I. G. 2011. Aminoacid composition of the ripe fruits of Solanuma ethiopicum and Solanum macrocarpon. International Journal of Pharmacy and Biology Sciences, 2 (2): 40-51.

[8] Nwodo S. C., Abayomi C. O., Eboji O. K., Opeyemi C. E., Olajumoke A. K. and Damilola I. D. 2011. Proximate and phytochemical analysis of Solanum aethiopicum L. and Solanum macrocarpon L. fruits. Research Journal of Chemical Sciences, 1 (3): 436-439.

[9] Nyadanu D., Aboagye L. M., Akromah R., Osei M. K. and Dordoe M. B. 2014. Agromorphological characterisation of gboma eggplant, an indigenous fruit and leafy vegetable in Ghana. African Crop Science Journal, Vol. 22, No. 4, pp. 281 - 289.

[10] Djé Y., Heuertz M., Lefebvre C. and Vekemans X. 2000. Assessment of genetic diversity within and among germplasm accessions in cultivated sorghum using microsatellite markers. Theor Appl Genet 100: 918-92.

[11] Baudoin J. P., Demol J., Louant B. P., Maréchal R. et Otoul E. 2002. Amélioration des plantes. Application aux principales espèces cultivées en régions tropicales. Les presses agronomiques de Gembloux. 581p.

[12] Demir K, Bakır M, Sarıkamış G, AcunalpS (2010) Genetic diversity of eggplant (Solanum melongena) germplasm from turkey assessed by SSR and RAPD markers. Genet Mol Res 9: 1568-1576.

[13] Behera TK, Sharma P, Singh BK, Kumar G, Kumar R, et al. (2006) Assessment of genetic diversity and species relationships in eggplant (Solanum melongena L.) using STMS markers. Scientia Hort 107: 352-57.

[14] Kumar S, Mangal M, Dhawan AK, Singh N (2011) Assessment of genetic fidelity of micropropagated plants of Simmondsia chinensis (Link) Schneider using RAPD and ISSR markers. Acta Physiol Plant 33: 2541-2545.

[15] Morgante M, Hanafey M, Powell W (2002) Microsatellites are preferentially associated with nonrepetitive DNA in plant genomes. Nature Genet 30: 194-200. 
[16] Nunome T, Negoro S, Kono I, Kanamori H, Miyatake K, et al. (2009) Development of SSR markers derived from SSRenriched genomic library of eggplant (Solanum melongena L.). Theor. Appl. Genet. 119: 1143-1153.

[17] Barchi L, Lanteri S, Portis E, Acquadro A, Valè G, et al (2011) Identification of SNP and SSR markers in eggplant using RAD tag sequencing. BMC Genomics 12: 304-13.

[18] Mangal M, Upadhyay P, Kalia P (2016), Characterization of cultivated and wild Brinjal genotypes (Solanum melongena L.) and confirmation of hybridity using microsatellite markers. Vegetables 29: 2. doi: 10.5958 / 2229-4473.2016.00016.1.

[19] Nunome T., Suwabe K., Iketani H. and Hirai M. 2003a. Identification and characterization of microsatellites in eggplant. Plant Breeding 122, 256-262.

[20] Maravilla A. M. B., Ocampo E. T. M., Canama A. O. and Delfin E. F. 2017. Hybridity Testing of Eggplant F1 Progenies Derived from Parents with Varying Response to Drought Using SSR Markers. Philippine Journal of Science 146 (3): 277-286.

[21] Saracanlao R J R., Ocampo E T M., Canama A O., Manaday S J B., Maghirang R G. and Delfin E F. 2016. SSR-Based Genetic Relationship in Eggplant (Solanum melongena) Genotypes with Varying Morphological Response to drought. Philipine Journal of Crop Science, vol 41 (3): 57-64.

[22] Aguoru C. U., Omoigui L. O. and Olasan J. O. 2015. Comparative Optimized procols of DNA Extraction and Purification Using FTA PlantSaver Card and DNAzol Methods for Eggplant (Solanum spieces) Studies in North Central Nigeria. Open Access Library Journal, p1-5.

[23] Sambrook J., Fritsch E. F. and Maniatis T., 1989. Molecular cloning. A laboratory manual. Vol. 3. Cold Spring Harbor, NY, USA: Cold Spring Harbor Laboratory Press.

[24] Adeniji O. T., Kusolwa P., Reuben S. O. W. M. and Deo P. 2012. Molecular diversity among seven Solanum (eggplant and relatives) species assessed by simple sequence repeats (SSRs) markers. African Journal of Biotechnology, Vol. 11 (90): 15643-15653.

[25] Borràs D., Plazas M., Andújar I., Gramazio P., Herraiz F. J., Prohens J. and Vilanova S. 2015. Molecular Characterization of Scarlet and Gboma Eggplants Based on Single Nucleotide Polymorphisms. BulletinUASVM Horticulture 72 (2), 448449. DOI: $10.15835 /$ buasvmen-hort: 11408 .
[26] Sawadogo B., Kiébré Z., Bationo-Kando P., Kiébré M., Traore R. E., Sawadogo N., Nanema K. Romaric, Ouedraogo M. H., Kabore B., Alleidi I. and Sawadogo M. 2018. Evaluation of Genetic Diversity of African Eggplant [Solanum aethiopicum (L.) sub sp Kumba] Using EST-SSR Molecular Markers. Int. J. Curr. Microbiol. App. Sci 7 (2): 2470-2479.

[27] Foulley J. L. and Ollivier L. 2006. Diversité génétique et richesse allélique: concepts et application à des races bovines. In: Treizièmes rencontres autour des recherches sur les ruminants, 6-7 décembre 2006, Paris, France, 227-230.

[28] Ben Naceur M., Belghouthi A., Chaabane R., El Fallah M. et Bettaeib-Ben Kaab L. 2008. Aptitude des marqueurs SSR à révéler le polymorphisme chez quelques génotypes d'orge (Hordeum vulgare, L.). Annales de l'INRAT, 81: 61-75.

[29] Ghosh, B. K., Mandal, A., Datta, A. K., Das, D. 2014. RAPD analysis in Andrographis paniculata (Burm. F.) ness plant types. Int. J. Res. Ayurveda Pharm. 5 (1), 84-88.

[30] Zhu X. C., Wu H. W., Raman H. and Lemerle D. 2012. Stanton R. and Burrows G. E., Evaluation of simple sequence repeat (SSR) markers from Solanum crop species for Solanum elaeagnifolium. Weed Research, 7p.

[31] Bationo-Kando P., Nanema K. R., Kiébre Z., Sawadogo B., Kiébre M., Nébie B., Sawadogo N., Traoré R. E., Sawadogo M., and Zongo J. D. 2015. Genetic diversity of cultivars of Kumba group (Solanum aethiopicum) assessed by EST-SSRS. International Journal of Development Research, Vol. 5, (10): 5686-5691.

[32] Ouédraogo M. H., 2016. Etude De La Diversité Génétique Des Gombos [Abelmoschus Esculentus (L.) Moench] Cultivés $\mathrm{Au}$ Burkina Faso. Thèse Unique de Doctorat, Université Ouaga I JKZ (Burkina Faso), Pp 165.

[33] Kiébré M. 2018. Diversité génétique de la corète potagère (Corchorus olitorius L.) du Burkina Faso. Thèse de doctorat, Université Ouaga I Pr JKZ., Burkina Faso. 120p.

[34] Wright S., 1978. Evolution and the Genetics of Population, Variability Within and Among Natural Populations. The University of Chicago Press, Chicago.

[35] Hartl D. L. and Clark A. G. 1997. Principles of Population Genetics, 3nd edn. Sinauer Associates, Inc, Sunderland, MA. 